\title{
Effect of Concept Mapping on Pedagogic Content Knowledge of Elementary Student Teachers
}

\author{
Ragisha.K.K ${ }^{1}$, Dr. K. Abdul Gafoor ${ }^{2}$ \\ ${ }^{1}$ [Senior Research Fellow Department of Education, University of Calicut] \\ ${ }^{2}$ [Associate Professor, Department of Education, University of Calicut]
}

\begin{abstract}
Teacher still has a prominent role in shaping the generations and teacher education institutions handle the responsibility of transformation of teachers. Teachers must have a thorough basis of the content and pedagogic practices for processing the knowledge to the level of students. This paper explores more effective ways of imparting content knowledge among elementary student teachers by comparing the effect of pedagogic analysis and concept mapping strategy on achievement in science of the 78 student teachers belonging to two elementary teacher preparation institutions. Quasi experimental pre-test post-test design with matched groups is employed for the study. The result shows that the experimental group that underwent concept mapping and control group that underwent pedagogic analysis differ significantly in the post test score after treatment. The study concludes that concept mapping can be used to impart content knowledge to student teachers with better effect than pedagogic analysis in teacher training institutions.
\end{abstract}

Key words: Concept mapping, Collaborative Concept mapping, Pedagogic analysis, conceptual understanding in Science, Elementary teacher education institutions.

\section{Introduction}

The key role of teacher education institutions in the development of quality teachers can never be overstated. At least since 1960's the professional preparation of teachers is recognized crucial for the qualitative improvement of education in general in India (Kothari Commission, 1964-66). However, teacher education programmes in India give more weight to subject neutral and uniform methodology of teaching at the expense of preparing future teachers strong in the pedagogic aspects of analysing, organizing, and evaluating the content of instruction from the learner perspective. This practice of teacher education continues despite the fact that in spite of high marks in plus two, teacher trainees show "inadequate" "insufficient" "marked deficiency" in the content knowledge and reveal "poor academic performance" (Gafoor\&Ragisha, 2012). While teacher educators report that student teachers' performance in instructional tasks like transaction process, style of teaching, and classroom evaluation practices depends upon the content level of teachers and hence, student-teachers require a thorough basis in the content knowledge, attempts to update, enhance and transform the way student teachers conceive subject matter of instruction is meagre in teacher education curricula. The problem gets compounded as vast majority of student teachers are the eliminates of other professional courses like medicine, engineering and career in administrative services and they consider the training programme as a mere 'passport' to a job in schools (Gafoor\&Ragisha, 2012).

Even as teacher educators realize the impact of deficiency in content knowledge on teaching outcomes, they feel unpowered to correct the situation as there is no space for filling in the gaps existing in subject matter competence of future teachers, and in further expanding and converting the content knowledge the latter had through their academic education in ways suitable for facilitating student learning. Teacher education curriculum in theory and practice neglect pedagogic content knowledge. The only space for equipping student teachers with content knowledge is pedagogic analysis of a few units the student teachers are assigned to teach during their teaching practice period. Most of the teacher educators belonging to self-financing institutions, which outnumber government and aided sector teacher education institutions in Kerala, limit the pedagogic analysis of the content to one or two units of the subject that are essential for successful completion of practice teaching. This too is done by way of educators dictating the facts and concepts involved in the unit to the student-teachers or at times, student teachers merely copying the relevant elements from the teachers' handbooks prepared by State Council of Educational Research and Training to their lesson plans. While rehauling teacher education curricula by keeping in mind the above limitations is overdue, that does not absolve the researchers and educators from seeking better ways to enhance student teachers' pedagogic content knowledge within the given curricular constraints. With a view to explore more effective ways of imparting content knowledge among student teachers within the constraints of the extant elementary teacher education curriculum, this study compares the effect of pedagogic analysis and concept mapping strategy on achievement in science of the student teachers belonging to elementary teacher preparation institutions. 


\subsection{Concept Mapping vis-à-vis Pedagogic Analysis In Teacher Education}

Pedagogical analysis stands for a type of analysis based on pedagogy. Pedagogy implies the science of teaching. Pedagogic analysis means a logical and systematic breakup of the curriculum from the point of view of a pedagogue or teacher for the purpose of its effective transaction. Process of preparing the curriculum is viewed through the eyes of a teacher with a sight of transactional phase of teaching where needs, capacities, and probable difficulties of the learners for whom it is transacted is the prime consideration. Analysis as a term stands for a process of breaking or separating a thing into its smaller parts, elements or constituents. Teachers break a teaching unit into its constituents - subunit, topics or single concepts through the process of unit analysis. In addition, teachers break the contents of the prescribed course in a subject into its various constituents- major and minor sections, units and sub-units, major concept and minor concepts, topics processes, facts, and terms by carrying out a process of content analysis. Therefore, "the analysis of a given content material in any subject, in any topic, carried out well in the spirit of the science of teaching (pedagogy) is known by the term pedagogic analysis of the contents" (Bhowmik, et al, 2013).

Concept mapping allows understanding the relationships between concepts in the form of propositions by creating a visual map of the connections. From a pedagogical perspective, this allows to see the connections between ideas already present, to connect new ideas to knowledge already gained and to organize ideas in a logical structure, and to provide flexibility to the existing knowledge structure to permit future information or viewpoints to be included. As a teaching strategy, concept maps derive from Ausubel's learning theory giving emphasis on the influence of previous knowledge on meaningful learning. Concept maps are graphical or diagrammatic representations showing meaningful relationships. Propositions are linked together by words and cross links. Concepts are arranged hierarchically with the main or super ordinate concepts at the top of the map and sub concepts or subordinate concepts at the bottom.

Using concept maps to focus upon the core elements in a discipline avoid fragmented or rote learning outcomes resulting in students' minimal understanding and transfer (Vitale \& Romance, 1992). Viable, deep understanding involves the hierarchical organization of conceptual knowledge into integrated and easily accessible schema, which 'helps the learner both to apply knowledge and acquire new knowledge (Reif \& Heller, 1982).Concept maps were used extensively in the field of school education to enhance achievement and have been successfully applied primarily to the learning of scientific subjects (Novak \&Musonda, 1991).

In spite of the evidenced strengths of this strategy to build up, maintain and re-organize one's structure of knowledge and the inclusion of teaching about concept mapping as an instructional strategy, the same is not attempted as strategy, apart from a few experiments (Gafoor \& Shareeja, 2011) to build up an integrated structure of content knowledge neither in school education nor in teacher education in Kerala, or India in general. Concept mapping tests to assess student teachers understanding of physics was found informative, engaging, reinforcing and providing immediate feedback, thus serving the real purpose of evaluation in Indian context (Gafoor \& Shareeja 2011). Using a principal concept map of a few concepts derived from apparently distinct topics and along with their corresponding sub concept maps give an idea on basic concepts in science and make student- teachers understand how these are interrelated, facilitating student teachers' easy and meaningful understanding of the basic concepts in school science (Gafoor \& Ragisha 2012).

\section{Objective Of The Study}

This study is to test whether there is significant difference between in the achievement in science of student teachers who performed concept mapping strategy of the content over the achievement of student teachers who performed conventional pedagogic analysis, using an experimental study.

\subsection{Design and sample of the study}

Quasi experimental pre-test post-test design with matched groups is employed for the study. Thirtynine students from one teacher training institution received concept mapping strategy and 39 students from a nearby teacher institution, belonging to the same category of management received pedagogic analysis. Both the groups belonging to unaided TTIs were matched on the basis of their marks in the qualifying examination, subject specialization in plus two level, gender, average age and marital status. The groups were statistically matched on the pre-test scores of conceptual understanding in science. On Pre-test, Mean (9.87), Median (9), and Mode (9) of CC Map group and the Mean (9.56), Median (10), and Mode (10) of PA group are almost equal. The mean scores of conceptual understanding in science of the experimental CC Map group $(M=9.87$, $\mathrm{SD}=2.62)$ was almost equal with the control PA group $(\mathrm{M}=9.56, \mathrm{SD}=2.10)$ before intervention $(\mathrm{p}>.01)$.

\subsection{Tools used for the study}

A pre-test of conceptual understanding in science based on the concepts involved in the first and second chapters of $5^{\text {th }}, 6^{\text {th }}$ and $7^{\text {th }}$ standards was prepared by following conventional objective-type achievement test development procedures. Another test, parallel to the pre-test in content and objective, was used as post-test. 
Both tests contained 28 items belonging to understanding and above objectives in Bloom's Taxonomy of cognitive domain. No questions were included from the knowledge domain.

\subsection{Procedure of the study}

Collaborative concept mapping lesson plans and pedagogic analysis on six selected units were developed. After pretesting, the experimental group received teaching of the science content through concept mapping strategy and the control group received pedagogic analysis of the selected lessons. Two hours each were spent for the completion of each of the six lessons in both strategies. The six topics selected for the instruction are

1. Aaharathinterahasyam (Secret of Food)

2. Enikkumvenamaarogyam (I too want health)

3. Kannadinannayaal (if your mirror is good)

4. Saseerathilekunjarakal (Cells of body)

5. Naamsamrakshikkendajalam (water to save)

6. Thaapampravarthikkumbol (when heat acts)

These six units are the first and second chapters of Basic Science text books for $5^{\text {th }}, 6^{\text {th }}$ and $7^{\text {th }}$ standards respectively.

\subsubsection{Collaborative concept mapping}

Collaborative concept mapping was done in groups of 4 to 5 students. In collaborative concept mapping, the major classroom activities in transacting the lesson include seven important elements. 1) Warmup: This consists of familiarizing the concept from the text book by reading the content. 2) Instruction: In this phase the teacher gives a detailed description of the topic which is an oral presentation supported by Black board and charts. As the student teachers belong to different subject streams at their higher secondary level, in this phase, student teachers from non- science streams are provided with opportunity to recall and refresh the facts, concepts, principles and procedures learned in their school grades. Concept mapping was attempted in student teachers, collaborative groups. Single row of the class room formed a group. The group included three to four students. 3) Preparation of Concept map: This includes five classroom transaction phases.

a. Brain storming phase where student teachers write down as many concepts they could recall in relation to the major concept to a paper in group.They write every terms, facts and concepts that they know about the topic. On an average each group of student teachers came up with more than thirty items on the concept per class.

b. Organizing phase categorise the concepts they listed within a group. and add concept that they remember during this phase. Student teachers noted down the concepts that fall into multiple for the facilitating organization of maps later.

c. Layout phase: Student teachers take a separate paper to represent their understandings among groups of concepts they have list down. The most important concept is placed at the top and subcategories are arranged below it in hierarchical relationships. Student teachers think about the connection words, between and within groups of concepts. Different groups of students came up with different arrangements of concepts.

d. Linking phase: Through discussions, student teachers made connections between concepts using arrows and linking words. Student teachers maintained hierarchy of concepts. Student teachers made meaningful connections within groups and between groups of concepts.

e. Finalizing the concept map: with a title after redrawing the final map by all members of the group was the culmination of preparation of the concept map.

4) Conclusion: here, student teacher shares their opinions within their groups and note down new points with other students. 5) Assessment of the map: This is done based on the importance given to the central topic and appropriateness of links and connections. Based on the assessment, points of improvements are shared among the groups.6)Extending the lesson: The instructor shows the expert made map and students compare maps constructed by them against the experts' maps and share and add the new concepts.7)Assignment: A follow- up mainly redrawing and elaboration of the map is given in this phase to be completed individually later.

\subsubsection{Pedagogic analysis}

Pedagogic analysis was also done in systematic manner. Steps in pedagogic analysis were: 1) Analysis of the unit into major themes (concepts) and minor themes (concepts). 2. Analysis of concepts into attributes. 3 . Identification of processes in the unit and analysis of these processes into hierarchical steps. 4. Identification of terms and explanation of meaning embedded in them. 5. Identification of pre-requisites needed for assimilating the new analysed concepts, process etc.6.Division of units into hierarchical lessons 7.Formulation of stage 
appropriate behavioural objectives for the whole unit.8. Listing of improvisation/ aids/ charts etc. for teaching the analyzed unit 9.Identifying historical events and current events that could enrich the learning of new materials.

\section{Results}

Comparison of Post Test in Conceptual understanding among Elementary student teachers after CC Mapping and Pedagogic Analysis was done using test of significance of difference and are presented in Table 1

Table 1 Data and Results of the Test of Significance of Difference between the Mean Scores of Post Test in Conceptual Understanding in Elementary Student Teachers after CC Mapping and Pedagogic Analysis

\begin{tabular}{lllll}
\hline Treatment groups & Mean & Standard Deviation & $\begin{array}{l}\text { Critical Ratio } \\
\text { t- value }\end{array}$ & Effect Size Cohen d \\
\hline CC Map group & 19.15 & 2.80 & $12.78^{* * *}$ & 3.25 \\
PA group & 11.79 & 2.26 & \\
\hline
\end{tabular}

$\mathrm{N}=39$

*** $\mathrm{p}<.01$

Table 1 shows that the critical ratio obtained for the comparison of mean post test scores of conceptual understanding for CC Map group and PA group is 12.78 is significant at .01 level. The significantly higher mean score of Post-test of CC Map group shows that after receiving the experimental treatment science conceptual understanding of $\mathrm{CC}$ Map group $(\mathrm{M}=19.15, \mathrm{SD}=2.80)$ is significantly higher than that of the PA group $(\mathrm{M}=$ $11.79, \mathrm{SD}=2.26$ ). Hence $\mathrm{CC}$ Mapping is more effective in developing science conceptual understanding in elementary student teachers than PA. CC Mapping has a strong effect on conceptual understanding in science of elementary student teachers, Cohen's $\mathrm{d}=3.25$. Effect size shows that $\mathrm{CC}$ mapping can be expected to improve conceptual understanding of elementary student teachers by over 3 standard deviations over PA.

\section{Discussion of the Results}

The experimental group and the control group differ significantly in the post test score after the treatment. Experimental group received a strategy named collaborative concept mapping and the control group received a detailed pedagogic analysis.

Concept mapping is a teaching strategy and it also helps the student to improve memory as it is a meaningful graphical representation. Learning with this strategy was a new experience to them and the students actively participated. Students can understand the ideas easily as the concepts are linked to each other through a meaningful connecting word. Here students get the opportunity to construct their own concept map and that increased the level of understanding by getting a clear map of the learned concepts. The students worked in groups of 4 to 5 students and discussions helped them to ideas acquire the concepts clearly. In the next phase students are introduced the expert made concept maps to correct their mistakes and also to expand their concept map. The concept map depicts the topic in detail. The mapping helped students to relate among the concepts and respond to testing and classroom situations with better judgement.

In the case of pedagogic analysis, students were not as motivated as in concept mapping groups. They require these analysed things at school during teaching practice phase which can be done with the help of lesson plans. Each concept was treated separately and no connections were established to concepts beyond the topic under discussion established. In this the unit is split to simple contents for the easy understandings of students they are going to teach. They will see as huge amount of information spreading in 5 to 6 pages. In the case of concept mapping there is a single page that contains the meaningful map which is easy to comprehend and relate to one another.

\section{Conclusion}

The experimental instruction of science through concept mapping strategy resulted in higher achievement of select science topics than detailed pedagogic analysis. Concept mapping is can be used to impart content knowledge to student teachers with better effect than pedagogical analysis in extant practice in Teacher Training Institutions in Kerala. The application of this strategy will help to improve the students teachers level of content knowledge without additional time investment technique of concept mapping can be employed as a learning strategy, as a method to capture the most significant aspect of a topic and as a resource with which to represent a set of conceptual meanings in complex science education knowledge domains. This if applied in teacher education will turn an efficient and helpful means for future teachers to retain long- term conceptual knowledge and engage in more complex thinking and improved reasoning that in turn brings in qualitative improvement in school education. So concept mapping can be the one of the strategies used for the fostering of content knowledge in the student teachers. 


\section{References}

[1]. Gafoor, A. K.\&Ragisha.K.K (2012) Status of pre- service elementary teacher education in Kerala: Educators view.in S.Sabu, (Ed.). Teacher Education in Thethe New Millenium. APH Publishing corporation, New Delhi.

[2]. Bhowmik.M.,Banerjee.B. \&Banerjee.J (2013) Role of pedagogy in effective teaching.Basic research journal of education research and review. http//www.basicresearchjournals.org.

[3]. Vitale. M. R.\&Romance.N. R. (1992) Content knowledge and methodology in teacher preparation- higher order thinking: designing curriculum for mainstreamed students.in D. Carnine\&E.Kameenui, (Eds.) Austin, Tex: PrO-ED, Inc.

[4]. Reif.F.\& Heller. J.I (1982) knowledge structure and problem solving in Physics. Educational psychologist 17: 102-27.

[5]. Novak JD and Musonda D (1991) A twelve-year longitudinal study of science concept learning. American Educational Research Journal 28(1): 117-53

[6]. Gafoor, A.K.\&Shareeja , A.M. (2011). Efficacy of concept maps to assess student teachers understanding of Physics. Endeavours in Education, 2(1) 